\title{
Flashbulb memories for Paris attacks in Korsakoff's syndrome: a case study
}

\author{
Marie-Charlotte Gandolphe ${ }^{1}$, Mohamad El Haj ${ }^{1,2}$ \\ 1 Univ. Lille, CNRS, CHU Lille, UMR 9193 - SCALab - Sciences Cognitives et Sciences Affectives, F-59000 Lille, France. \\ 2 Unité de Gériatrie, Centre Hospitalier de Tourcoing, Tourcoing, France.
}

Received: $12 / 27 / 2017$ - Accepted: 01/12/2018

Dol: 10.1590/0101-60830000000155

Gandolphe M-C, El Haj M / Arch Clin Psychiatry. 2018;45(2):49-50

\section{Dear Editor,}

Flashbulb memories are detailed, vivid and long-lasting autobiographical memories of attributes of the reception context of surprising and emotionally arousing public events ${ }^{1-5}$. We assessed flashbulb memories for the Paris attacks in a participant with Korsakoff's syndrome (KS).

\section{Method}

\section{Participant}

We recruited a participant with $\mathrm{KS}$ (Mr. T), a male, high-school graduates, right-handed, French native-speakers, living in his own homes with his wife and he had been abstinent for two years. Mr. $\mathrm{T}$ was 51 years old and had a 10-year-history of worsening alcohol abuse. He was diagnosed with KS based on the DSM-IV-TR criteria for alcohol-induced persistent amnesic disorder. Even though confabulations and anterograde amnesia persisted after the acute phase, Mr. T showed significant cognitive improvement, in addition to a significant change in volition and motivation for self-care.

\section{Flashbulb memory assessment}

Flashbulb memory was assessed using a directed interview technique, including questions on event memory, flashbulb memory, vividness, rehearsal, emotion, surprise, novelty and importance (see Annex).

\section{Verification}

To control for Mr. T's recall, we contacted his wife who confirmed that, during the Paris attacks, he was at home watching TV. However, the day of week when he first learned about the attacks was Friday and not Saturday.

\section{Discussion}

This is the first study to investigate flashbulb memories in KS. Although our participant tried to retrieve information for event memory, his retrieval was prone to distortion. Indeed, the attacks occurred on 13-November-2015 and not in February-2016, they did not occur at a metro station, nor was there a car bomb, as stated by the patient. These findings are important as they provide evidence on confabulations in KS for memory for real-life events, confabulations that have mainly been observed in laboratory studies. However, confabulations were not observed for flashbulb memories as the answers of Mr. T were confirmed by his wife, except for the day of week when he first learned about the attacks. Thus, flashbulb memories seem to trigger some reliable recall for the reception context. This finding is of interest as it may suggest some positive effect of flashbulb memories on context recall, a type of recall that has been found to be particularly affected in KS patients s-10. $^{\text {. }}$
Interestingly, our KS participant attributed high vividness to his recall. He also reported fair rehearsal and described the attacks as very negative. He further associated his recall with fair feelings, especially shock and sadness, as well as with fair surprise, novelty and importance. Hence, flashbulb memories triggered fair subjective reliving in $\mathrm{Mr}$. T., a finding of interest as, to our knowledge, no published study has assessed subjective reliving of autobiographical memory in KS. The same is true for studies on flashbulb memories in KS.

In closing, our study reveals a positive effect of flashbulb memories on recall of reception context of the Paris attacks in a case with KS. It also demonstrates extensive subjective reliving of flashbulb memories in this patient. By doing so, our work opens a window into the retrieval and subjective experience of emotional and consequential real-life events in patients with KS.

\section{Conflict of interest}

None.

\section{Annex}

\section{Flashbulb memory assessment}

\section{Event memory}

- On what date (day/month/year) did the attacks occur? Mr. T: February 2016.

- At what time did the attacks occur? Mr. T: In the evening.

- Where did the attacks occur? Mr. T: At a metro station.

- Do you remember anything else about the attacks? Mr. T: There was a car bomb.

\section{Flashbulb memory}

- Please describe how you first became aware of the attacks (radio, television, friend etc.).

Mr. T: I was home watching the TV.

- Please describe where you were when you learned about the attacks.

Mr. T: I was at home.

- Please describe who you were with when you learned about the attacks.

Mr. T: I was with my wife.

- Please describe what you were doing when you learned about the attacks.

Mr. T: Watching TV.

- What day of the week was it when you first learned about the attacks?

Mr. T: Saturday.

- What time was it when you first learned about the attacks? Mr. T: In the evening. 


\section{Vividness}

- When you think about the moment when you first learned about the attacks, do you see this moment in your mind? (not at all, a little, moderately, quite a bit, extremely)

Mr. T: Extremely.

- When you think about the moment when you first learned about the attacks, do you hear this moment in your mind? (not at all, a little, moderately, quite a bit, extremely) Mr. T: extremely

- When you think about the moment when you first learned about the attacks, do you feel that you are travelling back to the time it happened? (not at all, a little, moderately, quite a bit, extremely)

Mr. T: Extremely.

\section{Rehearsal}

- Since the announcement of the attacks, how closely have you followed the media coverage? (never, once, once a week, many times a week, every day)

Mr. T: Many times a week.

- Since its announcement, how many times have you thought about the attacks? (never, once, once a week, many times a week, every day)

Mr. T: Many times a week.

- Since its announcement, how many times have you talked about the attacks? (never, once, once a week, many times a week, every day)

Mr. T: Once a week.

\section{Emotion}

- Generally speaking, how do you evaluate your emotional reaction when you first learned about the attacks? (very negative, negative, neutral, positive, very positive)

Mr. T: Very negative.

When you first learned about the attacks, you were:

- (not at all shocked, a little shocked, moderately shocked, quite a bit shocked, very shocked)

Mr. T: Very shocked.

- (not at all confused, a little confused, moderately confused, quite a bit confused, very confused)

Mr. T: Quite a bit confused.

- (not at all sad, a little sad, moderately sad, quite a bit sad, very sad)

Mr. T: Very sad.

- (not at all angry, a little angry, moderately angry, quite a bit angry, very angry)

Mr. T: A little angry.

- (not at all afraid, a little afraid, moderately afraid, quite a bit afraid, very afraid)

Mr. T: Not at all afraid.

- (not at all anxious, a little anxious, moderately anxious, quite a bit anxious, very anxious)

Mr. T: Not at all anxious.

- (not at all insecure, a little insecure, moderately insecure, quite a bit insecure, very insecure)

Mr. T: Moderately insecure.

\section{Surprise}

- When you first learned about the attacks, you were (not at all surprised, a little surprised, moderately surprised, quite a bit surprised, very surprised)

Mr. T: Very surprised.

Novelty

- According to you, this event is (very unusual, a little unusual, moderately unusual, quite usual, very usual)

Mr. T: Very unusual.

\section{Importance}

- Is this event important to you? (not at all important, a little important, moderately important, quite a bit important, very important)

Mr. T: Moderately important.

- Is this event important to your family/friends? (not at all important, a little important, moderately important, quite a bit important, very important)

Mr. T: Moderately important.

- Is this event important to your country? (not at all important, a little important, moderately important, quite a bit important, very important)

Mr. T: Very important.

- Is this event important to the international community? (not at all important, a little important, moderately important, quite a bit important, very important) Mr. T: Very important.

\section{References}

1. Brown R, Kulik J. Flashbulb memories. Cognition. 1977;5(1):73-99.

2. Gandolphe MC, El Haj M. Flashbulb memories of the Charlie Hebdo attack. J Psychol Cogn. 2016;1(1):20-8.

3. El Haj M, Gandolphe MC, Wawrziczny E, Antoine P. Flashbulb memories of Paris attacks: Recall of these events and subjective reliving of these memories in a case with Alzheimer disease. Medicine (Baltimore). 2016;95(46):e5448.

4. El Haj M, Gandolphe MC. Flashbulb memories for Paris attacks in an alcohol-abstinent patient. J Syst Integr Neurosci. 2017;3(2):1-5.

5. Gandolphe MC, El Haj M. Flashbulb memories of the Paris attacks. Scand J Psychol. 2017;58(3):199-204.

6. Kessels RP, Kopelman MD. Context memory in Korsakoff's syndrome. Neuropsychol Rev. 2012;22(2):117-31.

7. Brion M, de Timary P, Pitel AL, Maurage P. Source memory in Korsakoff syndrome: disentangling the mechanisms of temporal confusion. Alcohol Clin Exp Res. 2017;41(3):596-607.

8. El Haj M, Nandrino JL, Coello Y, Miller R, Antoine P. Source monitoring in Korsakoff's syndrome: "Did I touch the toothbrush or did I imagine doing so?” Cortex. 2017;91:262-270.

9. El Haj M, Kessels RP, Matton C, Bacquet JE, Urso L, Cool G, et al Destination memory in Korsakoff's syndrome. Alcohol Clin Exp Res. 2016;40(6):1321-7.

10. Kessels RP, Kortrijk HE, Wester AJ, Nys GM. Confabulation behavior and false memories in Korsakoff's syndrome: role of source memory and executive functioning. Psychiatry Clin Neurosci. 2008;62(2):220-5. 